\title{
Dynamics and exact solutions of the generalized Harry Dym equation
}

\author{
Ruslan I. Matviichuk
}

\begin{abstract}
The Harry Dym equation is the third-order evolutionary partial differential equation. It describes a system in which dispersion and nonlinearity are coupled together. It is a completely integrable nonlinear evolution equation that may be solved by means of the inverse scattering transform. It has an infinite number of conservation laws and does not have the Painleve property. The Harry Dym equation has strong links to the Korteweg-de Vries equation and it also has many properties of soliton solutions. A connection was established between this equation and the hierarchies of the KadomtsevPetviashvili equation. The Harry Dym equation has applications in acoustics: with its help, finite-gap densities of the acoustic operator are constructed. The paper considers a generalization of the Harry Dym equation, for the study of which the methods of the theory of finite-dimensional dynamics are applied. The theory of finite-dimensional dynamics is a natural development of the theory of dynamical systems. Dynamics make it possible to find families that depends on a finite number of parameters among all solutions of evolutionary differential equations. In our case, this approach allows us to obtain some classes of exact solutions of the generalized equation, and also indicates a method for numerically constructing solutions.
\end{abstract}

\begin{abstract}
Анотація. Рівняння Гаррі Діма є еволюційним рівняння в частинних похідних третього порядку і описує системи з нелінійною дисперсією. Це цілком інтегровне нелінійне рівняння, яке може бути розв'язане за допомогою зворотнього перетворення розсіювання. Воно має нескінченну кількість законів збереження і не володіє властивостю Пенлеве. Рівняння Гаррі Діма тісно пов'язане з рівнянням Кортевега-де Вріса та має багато властивостей рівнянь з солітонними рішеннями. Раніше було встановлено зв'язок між даним рівнянням та ієрархіями рівняння КадомцеваПетвіашвілі. Воно також має застосування в акустиці: з його допомогою будуються скінченно-вимірні щільності акустичного оператора.
\end{abstract}

I express gratitude to Alexei G. Kushner for setting the problem and useful discussions. 2010 Mathematics Subject Classification: 35G20, 76M60 UDC 517.957

Keywords: evolutionary equations, dynamics, exact solutions, symmetry, jets. DOI: http://dx.doi.org/10.15673/tmgc.v12i4.1682 
В даній роботі розглядається узагальнення рівняння Гаррі Діма, для вивчення якого застосовуються методи теорії скінченновимірної динаміки еволюційних рівнянь в частинних похідних, що $є$ природнім розвитком теорії динамічних систем. Динаміка дає змогу знайти сім'ї розв'язків рівнянь в частинних похідних, які залежать від скінченного числа параметрів. У нашому випадку такий підхід дозволяє отримати деякі класи точних розв'язків узагальненого рівняння Гаррі Діма, а також вказує на можливість побудови числових методів для побудови їх розв'язків.

\section{INTRODUCTION}

The Harry Dym equation has the following form:

$$
u_{t}=u^{3} u_{x x x} .
$$

Apparently the first time this equation was given in paper [4] by M. Kruskal, which referred to an unpublished work by Harry Dym. This equation describes nonlinear dispersion processes and is closely related to the Korteweg-de Vries equation and the Kadomtsev-Petviashvili equation. The Harry Dym equation is used in acoustics to construct finite-gap densities of an acoustic operator [8]. It is a completely integrable nonlinear evolution equation, which can be solved using the inverse scattering problem.

This article is devoted to a generalized Harry Dym equation (GHD) of the form

$$
u_{t}=f(u) u_{x x x}
$$

for some function $f$. We suppose that the function $f$ belongs to a class $C^{\infty}$ in its domain of definition.

For such equations, first and second order dynamic will be constructed, which will then be used to construct their exact solutions.

The theory of finite-dimensional dynamics is a natural extension of the theory of dynamical systems to evolutionary partial differential equations. It describes a system in which dispersion and nonlinearity are coupled together.

A detailed description of this theory is presented in $[3,7]$. Here we give only the necessary definitions, ideas and results.

A method for constructing attractors for second-order evolutionary differential equations was proposed in [1], on the basis of which an algorithm for the numerical solution of such equations was developed in [6].

\section{Finite-Dimensional DynAmics}

Consider an ordinary differential equation of $(k+1)$-th order

$$
y^{(k+1)}=h\left(x, y, y^{\prime}, y^{\prime \prime}, \ldots, y^{(k)}\right) .
$$


This equation generates a one-dimensional distribution $\mathrm{P}$ on the jet space $J^{k}(\mathbb{R})$ such that its integral curves are prolongations of the solutions graphs into the space $J^{k}(\mathbb{R})$. The distribution $\mathrm{P}$ is generated by the vector field

$$
\mathcal{D}=\frac{\partial}{\partial x}+y_{1} \frac{\partial}{\partial y_{0}}+\cdots+y_{k} \frac{\partial}{\partial y_{k-1}}+h \frac{\partial}{\partial y_{k}},
$$

where $x, y_{0}, y_{1}, \ldots, y_{k}$ are coordinates on $J^{k}(\mathbb{R})$.

A vector field $X$ on $J^{k}(\mathbb{R})$ is called an infinitesimal symmetry of equation (2.1) if translations along $X$ save $P$.

Infinitesimal symmetries form Lie algebra Symm $P$ with respect to the Lie bracket. An infinitesimal symmetry is called characteristic if translations along it save each integral curve of the distribution P. Characteristic symmetries form an ideal in Symm $P$ which we denote by Char $P$.

The quotient Lie algebra Shuff $P:=$ Symm $P /$ Char $P$ is called the Lie algebra of shuffling symmetries.

Each shuffling symmetry can be identified with a vector field of the form

$$
S_{\phi}=\phi \frac{\partial}{\partial y_{0}}+\mathcal{D}(\phi) \frac{\partial}{\partial y_{1}}+\mathcal{D}^{2}(\phi) \frac{\partial}{\partial y_{2}}+\cdots+\mathcal{D}^{k}(\phi) \frac{\partial}{\partial y_{k}},
$$

where $\phi$ is a function on $J^{k}(\mathbb{R})$ that is called a generating function of the corresponding shuffling symmetry.

Let $y=y(x)$ be a solution of equation (2.1), $\phi$ a generating function of a shuffling symmetry, and $\Phi_{t}$ the translation along the vector field $S_{\phi}$. Then the function $u(t, x)=\left(\Phi_{t}^{-1}\right)^{*}(y(x))$ is a solution of the evolutionary partial differential equation

$$
\frac{\partial u}{\partial t}=\phi\left(x, u, u_{1}, u_{2}, \ldots, u_{k}\right)
$$

with the initial data $u(0, x)=y(x)$, where $u_{j}=\frac{\partial^{j} u}{\partial x^{j}}$.

Equation (2.1) is called a finite-dimensional dynamics of equation (2.2). The number $k+1$ is called an order of the dynamics.

The following theorem (see [1]) provides a method for calculating finitedimensional dynamics of evolutionary equations.

Theorem 2.1. The ordinary differential equation

$$
F=y_{k+1}-h\left(x, y_{0}, y_{1}, \ldots, y_{k}\right)=0
$$

is a dynamics of evolutionary equation (2.2) if and only if

$$
[\phi, F]=0 \bmod \mathbf{D F},
$$


where $\mathbf{D F}=\left\langle F, D(F), D^{2}(F), \ldots\right\rangle$ is the generated by the function $F$ differential ideal,

$$
D=\frac{\partial}{\partial x}+y_{1} \frac{\partial}{\partial y_{0}}+y_{2} \frac{\partial}{\partial y_{1}}+\cdots
$$

is the operator of total derivative, and

$$
[\phi, F]=\sum_{i \geqslant 0}\left(\frac{\partial \phi}{\partial y_{i}} D^{i}(F)-\frac{\partial F}{\partial y_{i}} D^{i}(\phi)\right)
$$

is a prolongation of the classical Poisson-Lie bracket into the jet space (see, for example, [5]).

\section{FIRST ORDER DYNAMICS}

Find first order dynamics of GHD equation (1.2) in the following form:

$$
F=y_{1}+A\left(y_{0}\right)
$$

where $A$ is a function. Then the Poisson-Lie bracket is

$$
[\phi, F]=f\left(y_{0}\right) A^{\prime \prime \prime}\left(y_{0}\right) y_{1}^{3}+3 f\left(y_{0}\right) A^{\prime \prime}\left(y_{0}\right) y_{1} y_{2}+f^{\prime}\left(y_{0}\right) y_{3} A\left(y_{0}\right) .
$$

Applying the operator of total differentiation by $x$ to the equation $F=0$, we obtain the following expressions of derivatives of the second and third order:

$$
\begin{aligned}
& y_{2}=-A^{\prime}\left(y_{0}\right) y_{1}, \\
& y_{3}=-A^{\prime \prime}\left(y_{0}\right) y_{1}^{2}-A^{\prime}\left(y_{0}\right) y_{2} .
\end{aligned}
$$

Then equation (2.3) has the form

$$
A^{2}\left(f^{\prime} A A^{\prime \prime}+f^{\prime} A^{\prime 2}+A f A^{\prime \prime \prime}+3 f A^{\prime} A^{\prime \prime}\right)=0 .
$$

This equation has the trivial solution $A\left(y_{0}\right)=0$ and nontrivial one

$$
\begin{aligned}
A\left(y_{0}\right) & = \pm \sqrt{-C_{1}\left(\int \frac{y_{0} d y_{0}}{f\left(y_{0}\right)}-y_{0} \int \frac{d y_{0}}{f\left(y_{0}\right)}\right) C_{2} y_{0}+C_{3}} \\
& = \pm \sqrt{C_{1} \iint \frac{1}{f\left(y_{0}\right)} d y_{0} d y_{0}+C_{2} y_{0}+C_{3}} .
\end{aligned}
$$

If $A\left(y_{0}\right) \neq 0$ and $C_{1} \neq 0$ for some constants $a, b$ then equation (3.2) can be solved with respect to the function $f$ :

$$
f\left(y_{0}\right)=\frac{C}{\left(A^{2}\left(y_{0}\right)\right)^{\prime \prime}},
$$

where $C$ is arbitrary constant. 
The restriction of the function $\phi$ to equation $F=0$ is

$$
\bar{\phi}=-f\left(y_{0}\right)\left(A^{2}\left(y_{0}\right) A^{\prime \prime}\left(y_{0}\right)-A\left(y_{0}\right)\left(A^{\prime}\left(y_{0}\right)\right)^{2}\right)
$$

Example 3.1 (Classical Harry Dym Equation). The function $f(u)=u^{3}$ corresponds to the classical Harry Dym Equation. In this case

$$
A\left(y_{0}\right)= \pm \sqrt{\frac{C_{1}+2 C_{2} y_{0}^{2}+2 C_{3} y_{0}}{2 y_{0}}} .
$$

To simplify the calculations, we put $C_{1}=2, C_{2}=C_{3}=0$ and suppose that $A\left(y_{0}\right)=\frac{1}{\sqrt{y_{0}}}$. Then the vector field

$$
\bar{S}=\frac{1}{\sqrt{y_{0}}} \frac{\partial}{\partial y_{0}} .
$$

Translations along this vector field from $t=0$ to $t$ and the inverse transformation are

$$
\begin{aligned}
\Phi_{t}:\left(x, y_{0}\right) & \longmapsto\left(x, \frac{1}{4}\left(8 y_{0}^{3 / 2}-12 t\right)^{2 / 3}\right), \\
\Phi_{t}^{-1}:\left(x, y_{0}\right) & \longmapsto\left(x,\left(\frac{3}{2} t+y_{0}^{3 / 2}\right)^{2 / 3}\right),
\end{aligned}
$$

and the general solution of the equation

$$
y^{\prime}+\frac{1}{\sqrt{y_{0}}}=0
$$

is

$$
y(x)=\frac{1}{4}(\alpha-12 x)^{2 / 3},
$$

where $\alpha$ is arbitrary constant. Its graph is shown in Figure 3.1.

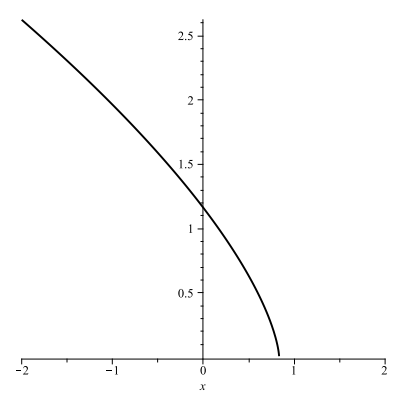

FiguRE 3.1. Graph of solution (3.3) with $\alpha=10$ 
Applying the transformation $\Phi_{t}^{-1}$ to this solution, we obtain the following solution of the classical Harry Dym equation:

$$
u(t, x)=\frac{1}{4}(8 \alpha-12(x+t))^{2 / 3} .
$$

Remark 3.2. Constructed solution (3.4) is similar to the solution obtained by an auto-Backlund transformation [2]:

$$
u(t, x)=\left(-3 \alpha\left(x+4 \alpha^{2} t\right)\right)^{2 / 3} .
$$

Example 3.3. Let $f(u)=u^{1 / 3}$ then

$$
A\left(y_{0}\right)= \pm \sqrt{C_{1} y_{0}^{5 / 3}+C_{2} y_{0}+C_{3}} .
$$

To simplify the calculations, we put $C_{1}=25, C_{2}=C_{3}=0$ and suppose that $A\left(y_{0}\right)=y_{0}^{5 / 6}$. Then the restriction of the function $\phi$ to the equation $F=0$ is $\bar{\phi}=-\frac{5}{9} y_{0}^{5 / 6}$ and the corresponding evolutionary vector field is

$$
\bar{S}=-\frac{5}{9} y_{0}^{5 / 6} \frac{\partial}{\partial y_{0}} .
$$

Then

$$
\begin{aligned}
\Phi_{t}:\left(x, y_{0}\right) & \longmapsto\left(x, \frac{15625}{24794911296}\left(t-\frac{54}{5} y_{0}^{1 / 3}\right)^{6}\right), \\
\Phi_{t}^{-1}:\left(x, y_{0}\right) & \longmapsto\left(x, \frac{15625}{24794911296}\left(t+\frac{54}{5} y_{0}^{1 / 3}\right)^{6}\right) .
\end{aligned}
$$

The general solution of the equation $y^{\prime}+y_{0}^{5 / 6}=0$ is

$$
y(x)=\frac{1}{46656}(x+\alpha)^{6},
$$

where $\alpha$ is arbitrary constant. Applying the transformation $\Phi_{t}^{-1}$ to this solution, we obtain the following solution of GHD equation:

$$
u_{t}=u^{1 / 3} u_{x x x}
$$

(see Figure 3.3):

$$
u(t, x)=\frac{1}{24794911296}(9(x+\alpha)+5 t)^{6} .
$$

Example 3.4. Let $f(u)=e^{u}$ then

$$
A\left(y_{0}\right)= \pm \sqrt{C_{1} y_{0}+C_{2} e^{y_{0}}+C_{3}} .
$$




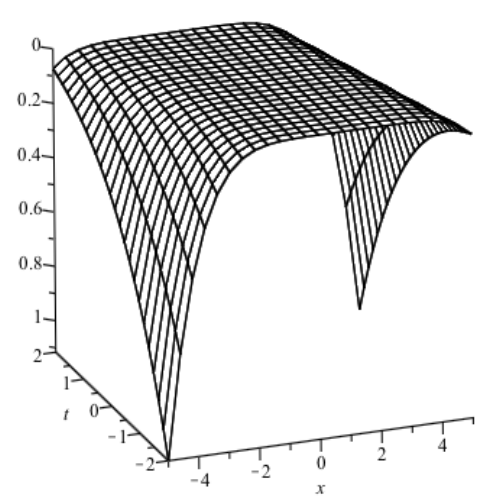

Figure 3.2. Graph of solution (3.5)

In order to simplify the calculations, put $C_{1}=0, C_{2}=-1, C_{3}=0$. Then $A\left(y_{0}\right)=e^{-\frac{y_{0}}{2}}$, whence $\bar{\phi}=-\frac{1}{2} e^{-y_{0} / 2}$, and

$$
\Phi_{t}:\left(x, y_{0}\right) \longmapsto\left(x,-\ln \frac{16}{\left(t e^{-\frac{y_{0}}{2}}-4\right)^{2}}+y_{0}\right)
$$

The general solution of the equation $y^{\prime}+e^{-y / 2}=0$ is

$$
y(x)=-\ln \frac{4}{(x+\alpha)^{2}},
$$

where $\alpha$ is arbitrary constant. Applying the transformation $\Phi_{t}^{-1}$ to this solution, we obtain the following solution of the GHD equation $u_{t}=e^{u} u_{x x x}$ :

$$
u(t, x)=-2 \ln \frac{4}{(2(x+\alpha)+t)^{2}} .
$$

(see Figure (3.4))

\section{SECOND ORDER DYNAMiCS}

In this section we will describe the second order dynamics of the equation (1.2) in the following form:

$$
F=y_{2}+A\left(y_{0}\right) y_{1}+B\left(y_{0}\right)
$$




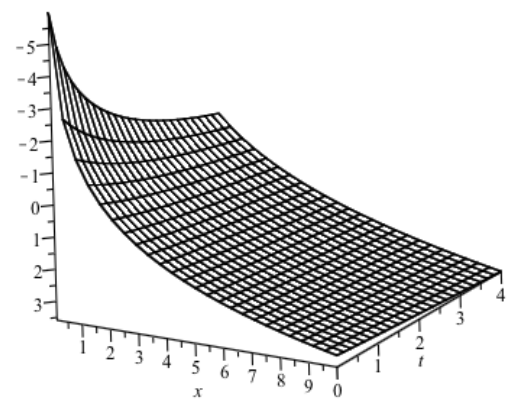

Figure 3.3. Graph of solution (3.6)

where $A, B$ are some functions. Notice that the equation 2.3 can be written as the following overdetermined system:

$$
\left\{\begin{array}{l}
B^{2}\left(3 f A^{\prime}+A f^{\prime}\right)=0, \\
3 B\left(-f B^{\prime \prime}+\left(A^{2}-B^{\prime}\right) f^{\prime}+3 f A A^{\prime}\right)=0, \\
f A^{\prime \prime \prime}+2 f^{\prime} A^{\prime \prime}+A^{\prime} f^{\prime \prime}=0, \\
-6 f A A^{\prime \prime}+f B^{\prime \prime \prime}+2 f^{\prime} B^{\prime \prime}-8 A A^{\prime} f^{\prime}+\left(B^{\prime}-A^{2}\right) f^{\prime \prime}-3 f\left(A^{\prime}\right)^{2}=0, \\
-6 f B A^{\prime \prime}-3 f A B^{\prime \prime}-A B f^{\prime \prime}+\left(-7 f^{\prime} B+\left(6\left(A^{2}-\frac{1}{2} B^{\prime}\right)\right) f\right) A^{\prime}+ \\
+2 A f^{\prime}\left(A^{2}-2 B^{\prime}\right)=0 .
\end{array}\right.
$$

Solving this system for nontrivial $f$ (i.e. $f \neq 0$ ) we get three solutions:

(1) $A=B=0, f$ is arbitrary;

(2) $A=0, B=C_{1}+C_{2} \int \frac{d y_{0}}{f\left(y_{0}\right)}, f$ is arbitrary;

(3) $A= \pm \frac{1}{\sqrt{C_{1} y_{0}+C_{2}}}, B=C_{3}+C_{4} \int A^{3} d y_{0}, f=\frac{C_{5}}{A^{3}}$,

where $C_{1}, \ldots, C_{5}$ are arbitrary constants.

Consider these cases sequentially.

Case 1. Equation (4.1) has the form $y^{\prime \prime}=0$. But since $\bar{\phi}=0$, the vector field $\bar{S}=0$ vanishes and we cannot construct solutions of equation (1.2).

Case 2. Equation (4.1) has the form

$$
y^{\prime \prime}+C_{1}+C_{2} \int \frac{d y_{0}}{f\left(y_{0}\right)}=0
$$


and $\bar{\phi}=-C_{2} y_{1}$. Therefore

$$
\bar{S}=-C_{2} y_{1} \frac{\partial}{\partial y_{0}}-C_{2}\left(C_{1}+C_{2} \int \frac{d y_{0}}{f\left(y_{0}\right)}\right) \frac{\partial}{\partial y_{1}} .
$$

Case 3. Equation (4.1) has the form

$$
y^{\prime \prime}+\frac{y_{1}}{\sqrt{C_{4} y_{0}+C_{2}}}-\frac{2 C_{2}}{C_{4} \sqrt{C_{4} y_{0}+C_{2}}}+C_{1} .
$$

For simplicity, put $C_{1}=a, C_{2}=b, C_{3}=C_{4}=0, C_{5}=c$ and suppose that the function $A$ is positive, i.e.

$$
A\left(y_{0}\right)=\frac{1}{\sqrt{a y_{0}+b}}, \quad B\left(y_{0}\right)=0, \quad f\left(y_{0}\right)=c\left(a y_{0}+b\right)^{3 / 2} .
$$

Then the equation (4.1) will have the form

$$
y^{\prime \prime}+\frac{1}{\sqrt{a y+b}}=0
$$

and its solution can be found in implicit form:

$$
\begin{gathered}
-4 C_{1} \sqrt{a y+b}-2 \operatorname{arctanh}\left(2 C_{1} \sqrt{a y+b}\right), \\
\pm \ln \left(4 C_{1}^{2} a y+4 b C_{1}^{2}-1\right) \mp 2 \ln C_{1}+4 C_{1} x+C_{2}=0,
\end{gathered}
$$

where $C_{1}, C_{2}$ are constants. Note that the function $y$ is 2 -valued. Since the vector field (2.4) has the form

$$
\mathcal{D}=\frac{\partial}{\partial x}+y_{1} \frac{\partial}{\partial y_{0}}+\frac{y_{1}}{\sqrt{a y_{0}+b}} \frac{\partial}{\partial y_{1}},
$$

the restriction of the function $\phi$ to the equation $F=0$ is

$$
\bar{\phi}=\frac{c}{2} y_{1}\left(2 \sqrt{a y_{0}+b}+a y_{1}\right) \text {. }
$$

and the corresponding evolutionary vector field is

$$
\bar{S}=\frac{c y_{1}}{2}\left(2 \sqrt{a y_{0}+b}+a y_{1}\right) \frac{\partial}{\partial y_{0}}+\frac{c y_{1}\left(3 a y_{1}+2 \sqrt{a y_{0}+b}\right)}{2 \sqrt{a y_{0}+b}} \frac{\partial}{\partial y_{1}} .
$$

This vector field generates the shift transformation $\Phi_{t}$. Applying the transformation $\Phi_{t}^{-1}$ to the expression, we get an implicit representation of the solution to GHD equation

$$
u_{t}=c(a u+b)^{3 / 2} u_{x x x}
$$

Unfortunately, shift transforms cannot be found explicitly, but one can use the method of numerical integration. 


\section{REFERENCES}

[1] A. V. Akhmetzyanov, A. G. Kushner, V. V. Lychagin. Attractors in filtration models. Dokl. Akad. Nauk, 472(6):627-630, 2017.

[2] F. Gesztesy, K. Unterkofler. Isospectral deformations for Sturm-Liouville and Dirac-type operators and associated nonlinear evolution equations. Rep. Math. Phys., 31(2):113137, 1992, doi: 10.1016/0034-4877 (92) 90008-0.

[3] Boris Kruglikov, Olga Lychagina. Finite dimensional dynamics for KolmogorovPetrovsky-Piskunov equation. Lobachevskii J. Math., 19:13-28, 2005.

[4] Martin Kruskal. Nonlinear wave equations. pages 310-354. Lecture Notes in Phys., Vol. 38, 1975.

[5] Alexei Kushner, Valentin Lychagin, Vladimir Rubtsov. Contact geometry and non-linear differential equations, volume 101 of Encyclopedia of Mathematics and its Applications. Cambridge University Press, Cambridge, 2007.

[6] A. M. Salnikov, A. V. Akhmetzianov, A. G. Kushner, V. V. Lychagin. A numerical method for constructing attractors of evolutionary filtration equations. In 2019 1st International Conference on Control Systems, Mathematical Modelling, Automation and Energy Efficiency (SUMMA), pages 22-24. IEEE, 2019, doi: 10.1109/summa48161.2019.8947585.

[7] Lychagin Valentin, Lychagina Olga. Finite dimensional dynamics for evolutionary equations. Nonlinear Dynam., 48(1-2):29-48, 2007, doi: 10.1007/s11071-006-9049-5.

[8] D. V. Zakharov. Isoperiodic deformations of an acoustic operator, and periodic solutions of the Harry Dym equation. Teoret. Mat. Fiz., 153(1):46-57, 2007, doi: $10.1007 / \mathrm{s} 11232-007-0122-0$.

Received: September 18, 2019, accepted: December 7, 2019.

Ruslan I. Matviichuk

Lomonosov Moscow State University, GSP-2, Leninskie Gory, Moscow, 119991, Russia

Email: mathvich@gmail.com 